compared with those of a series of unoperated children reported from South Wales.

This work was carried out with the help of a grant from the Research Committee of the United Liverpool Hospitals and the I.iverpool Regional Hospital Board.

\section{REFERENCBS}

Burns, R. (1967). Dev. med. Child Neurol., to be published. Doran, P. A., and Guthkelch, A. N. (1961). F. Neurol. Neurosurg.
Psychiat., 24, 331.
Eckstein, H. B., and Macnab, G. H. (1966). Lancet, 1, 842.

Forrester, R. M. (1965). Ibid., 1, 262.

Laurence, K. M. (1964). Arch. Dis. Childh., 39, 41.

- (1966). Dev. med. Child. Neurol., Suppl. No. 11, p. 10.

Lindon, R. L. (1963). Ibid., 5,125 .

Lorber, J. (1965). Proceedings of a Symposium on Spina Bifida. National Fund for Research into Poliomyelitis and other Crippling Diseases, London.

Rickham, P. P. (1964). Ann. roy. Coll. Surg. Engl., 35, 84.

and Mawdsley, T. (1966). Dev. med. Child Neurol., Suppl. No.

11, p. 20 . W. W., Zachary, R. B., Lorber, J., and Bruce, A. M. (19632 Arch. Dis. Child., 38, 18.

\title{
Early Closure of Myelomeningocele, with Special Reference to Leg Movement
}

\author{
G. BROCKLEHURST,* F.R.C.S.; J. R. W. GLEAVE, ${ }^{*}$ F.R.C.S. ; WALPOLE LEWIN,* M.S., F.R.C.S.
}

Brit. med. . ., 1967, 1, 666-669

Myelomeningocele is a relatively common anomaly, the surgical attitude to which has changed over the past few years to a more active approach. This has been encouraged by advances in the general management of paraplegia and its complications and the more successful surgery of hydrocephalus. The extensive surveys by Laurence (1964) of the natural history of spina bifida have established that many infants with this defect die within the first six months of life, but that there is an appreciable natural survival rate thereafter. He also showed that there was an increased chance of survival into later life of children whose myelomeningocele had been treated surgically compared with similar but untreated patients, though these observations reflect the kind of selective surgery which was practised a decade ago. Doran and Guthkelch (1961) reported a $70 \%$ survival rate in a large group of patients selected for surgery between the third and twelfth months of life, whereas those rejected for surgery (over $40 \%$ of the total) showed only a $7.5 \%$ survival rate.

In considering the question of when to repair the spinal defect, Guthkelch (1962a) initially reported very poor results from operating on a small series within the first 24 hours of life, but more recently he reported a series of cases closed within 24 hours of birth with a $19 \%$ mortality (Guthkelch, 1965). A great stimulus was added to the early closure of these lesions when Sharrard, Zachary, Lorber, and Bruce (1963) published the results of a controlled trial of immediate closure and nonoperative management. The mortality of both groups was high, but in the operated group muscle function had improved in some of the survivors, whereas it had deteriorated in some who had survived on conservative management (Sharrard et al., 1963).

In 1963 it was decided to study a consecutive series of 25 infants with myelomeningocele closed within the first 24 hours of birth; to investigate the reasons for the high mortality of this kind of surgery so far reported ; to ascertain the significance of stimulation of the involved neural tissue at the time of operation; and to see whether the suggestion that early closure promotes improvement in muscle function of the legs could be confirmed.

\section{Material}

Between July 1963 and June 196525 infants with open myelomeningocele were referred from the East Anglian Region to the department of neurological surgery and neurology at
Cambridge shortly after birth. With the exception of one patient who was rejected for surgery because of multiple congenital anomalies outside the nervous system, all were operated on within 24 hours of birth.

During this period 14 other infants with myelomeningocele were not referred from the region for surgery, and a further five who were admitted to the department have not been included in this series, as they reached us later than 24 hours after birth. Two of this group who underwent surgery between 24 and 48 hours after birth developed meningitis-a fact which confirmed our decision to aim for closure within the first 24 hours of life.

An investigation into the number of children born alive with myelomeningocele in the East Anglian Region over a period of three years suggests that the total is between 25 and 30 a year. Based on the Registrar-General's figures for the population of the East Anglian Region (1,604,700 in 1964), the crude birth rate for the same year (17.7 per 1,000), and the average incidence for England and Wales of live-born children with spina bifida, there should be a theoretical incidence in East Anglia of 37.5 cases per annum. It seems possible, therefore, that the incidence in East Anglia is below the national average. There seems little doubt from the work of Record and McKeown (1949) Stevenson and Warnock (1959), Guthkelch (1962b), and Laurence (1965) that there are considerable regional variations, but that in general the incidence of these malformations is higher in the west than in the east of the British Isles.

The infants were transferred after discussion with the referring practitioner or paediatrician, and the purpose and prognosis of surgical treatment were explained to one or both parents at this stage. A specimen of maternal blood accompanied the infant on transfer.

\section{Management}

The general assessment and management of the infants was conducted in conjunction with the paediatricians. On admission a full general examination and a total body $\boldsymbol{x}$-ray examination were carried out. The size, appearance, and site of the lesions were noted (Table I). The neurological deficit was carefully assessed, and particular attention was paid to the size

- From the Department of Neurological Surgery and Neurology, Addenbrooke's Hospital, Cambridge. 
Reflexes.-Spinal reflex phenomena were observed in 18 of the 25 cases. The spinal reflex phenomena were particularly active in the first three weeks postoperatively, but later became much more obviously detached and could be elicited only by stimulation of sites such as the perineum, adductor region, and plantar surfaces in patients showing no spontaneous leg movements whatsoever. Nine of the 18 are now totally paraplegic, and in the nine with some normal leg movement the spinal reflexes were elicited from below the level of normal movement.

\section{Nerve Stimulation Results and Relation to Function}

The nervous tissue exposed at operation was stimulated by a square-wave pulse at a repetititve frequency of 50 cycles a second. In 13 cases stimulation of the nerve roots attached to the neural plaque at 0.5 to 2 volts produced movements in muscles which had shown no spontaneous activity before operation; no useful activity developed in these muscles postoperatively. In seven cases similar movements could also be elicited from the plaque itself with the use of low-volt stimulation; again no useful movement developed postoperatively. In four cases a higher voltage was required to stimulate the plaque, and it was concluded that the plaque when covered by granulation tissue had a high impedance to electrical stimulation. It was noted that in two cases where the lesion was very asymmetrical, with plaque and abnormal roots on one side at a much higher level than the other, stimulation of the abnormal tissue at a low voltage produced movements, whereas stimulation of the more normal tissue required a higher voltage. There appeared to be some correlation between electrical excitability and clinical neurological deficit. It was also observed that stimulation of the plaque was more effective in the area close to the midline, which appeared to correspond to the basal lamina of embryological development.

\section{Discussion}

The low mortality in this series of 25 consecutive myelomeningocele patients submitted to surgical closure within the first 24 hours of birth, with no deaths in the immediate postoperative phase and a survival up to three months of $88 \%$, has been maintained in the total series of 40 patients to date. We related the low incidence of local sepsis and the absence of meningitis to the policy of achieving closure of these lesions within the first 24 hours of birth, to the technique of closure, and to the optimal anaesthetic and theatre conditions under which the surgery was performed.

Guthkelch (1965), in his more recent series of early closure of myelomeningoceles, also obtained considerable reduction in the incidence of infection, and made the further point that rapidly progressing hydrocephalus endangers the success of surgical closure. Our experience confirms this observation. We adopted a very active approach to the hydrocephalus, and proceeded to a ventriculo-atrial shunt as soon as there was any clinical indication of this complication, such as tight anterior fontanelle, a bulging or leaking myelomeningocele wound, or clinical evidence of raised intracranial pressure in addition to an abnormal rate of increase in skull circumference. In a few cases the shunt procedure was performed at the same time as the surgical closure of the myelomeningocele.

It would therefore seem, as might be expected on general surgical principles, that early closure of the open type of myelomeningocele will result in a considerable improvement in the survival rate of these infants when compared with the natural history of the condition over the first few months of life (Laurence, 1964; Guthkelch, 1965). The most recent analysis of the neurological state of this series (Table III) indicates that the survivors will include almost $50 \%$ of children with total paraplegia and a further group with moderate disability. Only $12 \%$ will have good leg function. The survival of many children with a profound neurological deficit must be taken into account in any planning which is made in a particular area for the future management of these patients, and in the overall evaluation of early surgery.

The effect of successful early closure upon the neurological function of the lower limbs must be related to the known pathology of these lesions, which varies from those cases with a widely open and flattened spinal cord exposed on the surface from the thoracic region downwards, to those where the lesion consists of a membranous sac in the sacral region containing a few roots or a small plaque of glial tissue related only to the cauda equina. In the disorganized cord tissue there are many anterior-horn cells, and the occurrence of muscle activity in the myotomes supplied by this region is in no way surprising. The results of stimulation at operation not only have confirmed at least the efferent side of the pathways determining these segmental and intersegmental activities but have also suggested that both the nerve roots and neural plaque are highly active in the newborn, and can be stimulated by very low voltage and occasionally by the lightest touch. The results of nerve stimulation suggest that there is a direct relation between the occurrence of spinal reflexes and the excitability of nerve roots and neural plaque, and an inverse relation between this excitability and the neurological function under higher control. The clinical observations which we have made upon the spinal reflexes of these infants suggest that these reflexes may not be fully apparent within the first few hours of birth, particularly in the infant who arrives somewhat chilled after transfer from one hospital to another, but they appear very prominently during the first three months of life and tend to diminish thereafter. These observations are very much in accordance with those made previously (Guthkelch, 1964).

Surgical closure of these lesions within the first 24 hours of birth would appear to be the most direct method of preventing further damage to the exposed neural tissue, which is clearly of paramount importance in the minority of infants with low lesions and a minimal neurological deficit. It is also possible that the preservation of function in the neural plaque by early cover with dura and skin may be of some advantage with regard to the retention of micturition and to defaecation at a reflex level in paraplegic patients.

In our neurological assessment of these patients we endeavoured to distinguish spinal reflexes from spontaneous activity. The grading of power in individual muscle groups as used by Sharrard et al. (1963), based upon the M.R.C. method of scoring which was primarily designed for the assessment of recovery of peripheral nerve lesions (Sharrard et al., 1963), is not only difficult to apply to the uncooperative newborn infant with any numerical accuracy, but is also probably inapplicable to the neurological lesions of infants with myelomeningocele and cord lesions. Assessments based upon handling of the limbs and direct faradic stimulation of muscles will merely distinguish between innervated and denervated muscles, but will give no information about the voluntary control of rauscle groups. They will also fail to distinguish those which are innervated by anterior-horn cells within the abnormal neural plaque but nevertheless have an upper motor neurone lesion. The method which we have used in the assessment of this series is simpler but is probably more relevant to the neurological state and future function of the legs. It has the disadvantage that minor degrees of hip extension and plantar flexion of the ankles may not be appreciated. It is difficult also to distinguish between knee flexion which occurs as a result of gravity and spontaneous knee flexion, without handling the limbs. It is also clear from our results that the true state of the leg movements is much more apparent six months after operation. The apparent improvement occurring in a number of cases over the first three months after operation is probably the temporary manifestation of spinal reflexes. 


\section{Summary and Conclusions}

The mortality in a series of 25 infants with myelomeningocele closed within the first 24 hours of birth was $12 \%$ over the first three months.

Neurological assessment of the survivors with particular attention to leg movements has indicated that spinal reflex phenomena are common, and that, though there may be apparent improvement in some cases within the first few weeks after operation, the later results show that there is no significant increase in useful leg function compared with the preoperative levels.

Early closure would appear to have prevented the death of these infants, and to have preserved the useful leg movements with which they were born, but not to have led to any significant recovery.
We wish to thank the consultant paediatricians in the East Arglian Region for their help in this study, and in the management of these infants ; Dr. D. M. T. Gairdner and Dr. J. D. Roscoe (Cambridge), Dr. R. M. Mayon-White (Ipswich), Dr. B. W. Powell (Peterborough), Dr. J. F. P. Quinton (Norwich), and Dr. R. C. Roxburgh (King's Lynn).

\section{REFERENCES}

Doran, P. A., and Guthkelch, A. N. (1961). F. Neurol. Neurosurg. Psychiat., 24, 331.

Guthkelch, A. N. (1962a). Ibid., 25, 137.

- (1962b). Brit. F. prev. soc. Med., 16, 159

(1964). Develop. Med. child Neurol., 6, 264

(1965). Acta neurochir (Wien), 13,407.

Laurence, K. M. (1964). Arch. Dis. Childh., 39, 41.

- (1965). Develop. Med. child Neurol., Suppl. No. 11, p. 10.

Record, R. G. and McKeown, T. (1949). Brit. J. prev. soc. Med., 3,183

Record, R. G., and Mckeown, T. (1949). Brit. F. prev. soc. M. M. (1963) Arch. Dis. Childh., 38, 18.

Stevenson, A. C., and Warnock, H. A. (1959). Ann. hum. Genet., 23, 382 .

\title{
Scabies: Another Epidemic?
}

\author{
ALAN B. SHRANK,* M.A., B.M., B.CH., M.R.C.P.; SUZANNE L. ALEXANDER, † M.B., B.S.
}

Brit. med. F., 1967, 1, 669-671

Several infectious diseases are legally notifiable so that epidemics can be readily detected and appropriate steps taken by public health authorities. Some infectious diseases, such as scabies, are not notifiable, and fluctuations in their incidence may be appreciated only by those treating them, and an epidemic may remain unrecognized until it is well advanced. This paper reports a recent rise in the prevalence of scabies at St. John's Hospital for Diseases of the Skin, London, where nearly 15,000 new outpatients are seen each year. 'An attempt is made to account for the rise. A few case histories are recorded, in which the diagnosis of scabies had been overlooked by the referring doctor, in order to emphasize the serious consequences of mistaken diagnosis and the need to consider this diagnosis in anyone with pruritus.

\section{Method}

The number of patients diagnosed as having scabies as well as syphilis and pediculosis and the total number of new outpatients seen each year since 1952, when the diagnostic index began, were recorded. The case notes of those seen in 1961 and in 1965 were examined, and those in whom the diagnosis was proved by microscopy were selected for study. 1961 was chosen because the incidence that year was similar to the preceding eight and the subsequent two years, while 1965 was chosen because the rise was most pronounced that year. The age, sex, marital status, whether the referring doctor had suspected scabies, and whether contacts had also attended the hospital were recorded.

\section{Results}

The incidence of scabies can be seen in Table $I$; the average was $0.9 \%$ (range 0.6 to $1.2 \%$ ) of all new patients seen from 1952 until 1963 , but in 1964 it rose to $1.4 \%$, in 1965 to $2.1 \%$, and in 1966 to $2.4 \%$. In 1961, of the 118 thought to have scabies

\footnotetext{
- Dermatologist, Royal Salop Infirmary, Shrewsbury, Shropshire. Late Tutor in Dermatology, St. John's Hospital for Diseases of the Skin, London W.C.2.

+ Research Associate, Guy's Hospital, London S.E.1 ; Clinical Assistant,
} St. John's Hospital for Diseases of the Skin, London W.C.2. proof was obtained in 103, of whom $58(57 \%)$ were men, while in 1965256 of the 293 were proved to have scabies, of whom $156(61 \%)$ were men. Fig. 1 gives more data for those proved to have scabies; the age groupings are arbitrary. The major increase is in single young people aged 16 to 21 , sixfold in the

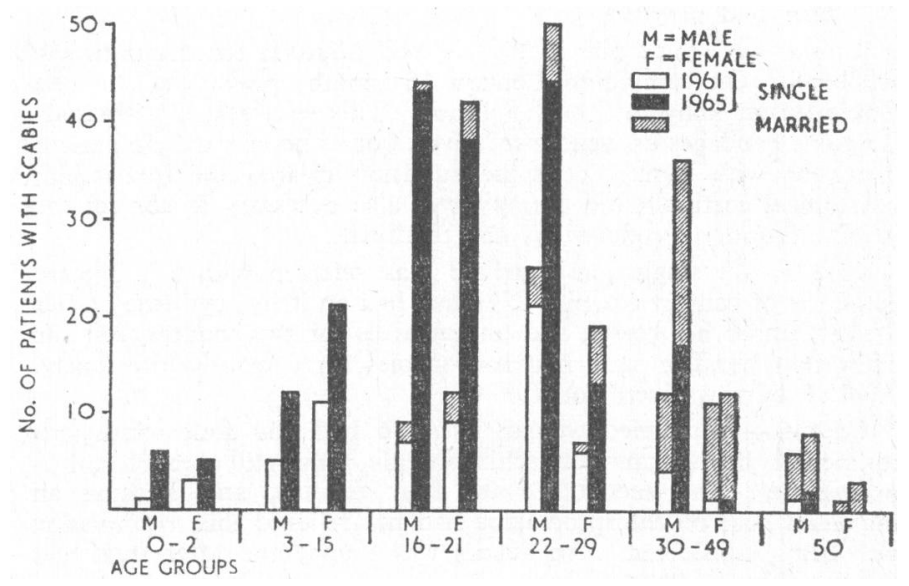

Fig. 1 shows the numbers of new patients with scabies attending St John's Hospital for Diseases of the Skin, London, in 1961 and 1965 , according to age, sex, and marital status.

TABLE I.-Numbers of Outpatients with Scabies, Pediculosis, and Syphilis and the Total New Outpatients Attending St. Fohn's Hospital for Diseases of the Skin, London, from 1952 to 1966

\begin{tabular}{c|c|c|c|c} 
Year & Scabies & Pediculosis & Syphilis & $\begin{array}{c}\text { Total New } \\
\text { Outpatients }\end{array}$ \\
\hline 1952 & 128 & - & -18 & 18,628 \\
1953 & 120 & 18 & 12 & 17,302 \\
1954 & 152 & 18 & 5 & 15,812 \\
1955 & 145 & 18 & 2 & 14,524 \\
1956 & 164 & 11 & 6 & 14,969 \\
1957 & 166 & 14 & 4 & 13,836 \\
1958 & 116 & 19 & 6 & 13,832 \\
1959 & 136 & 14 & 3 & 13,556 \\
1960 & 158 & 14 & 15 & 15,037 \\
1961 & 118 & $18(10)$ & 7 & 12,654 \\
1962 & 119 & $13(7)$ & 12,597 \\
1963 & 101 & $12(3)$ & 4 & 14,079 \\
1964 & 190 & $15(7)$ & 11 & 14,173 \\
1965 & 293 & $20(15)$ & $23(14)$ & 13,836 \\
\hline
\end{tabular}

Figures in parentheses $=$ numbers with phthiriasis. 